\title{
DEBATE
}

\section{Arguments at cross-purposes: moral epistemology and medical ethics}

\section{Loughlin}

J Med Ethics 2002;28:28-32

Different beliefs about the nature and justification of bioethics may reflect different assumptions in moral epistemology. Two alternative views (put forward by David Seedhouse and Michael H Kottow) are analysed and some speculative conclusions formed. The foundational questions raised here are by no means settled and deserve further attention.

Correspondence to: Dr M Loughlin, Department of Humanities and Applied Social Studies, Manchester Metropolitan University, Alsager Campus, Hassal Road, Stoke-on-Trent, ST7 2HL,UK;

m.loughlin@mmu.ac.uk

Revised version received 6 May 2001

Accepted for publication

7 May 2001 n August 1999 the Journal of Medical Ethics published a debate between Michael Kottow ${ }^{12}$ and David Seedhouse. ${ }^{3}$ Both authors raised foundational questions about the nature and assumptions of bioethical discourse. Unfortunately these important questions have by no means been adequately resolved and yet the debate appears to have been abandoned by the authors. In what follows I argue that the differences between them may reflect different assumptions about moral epistemology. The authors presuppose accounts of the nature of moral thinking which determine different, and probably incompatible, beliefs about the nature and scope of "moral knowledge" -what it means to know that an action or practice is morally right or acceptable, how it is possible to know this and what types of action or practice can meaningfully be subjected to moral criticism. The fundamental nature of these differences might help to explain the seemingly futile nature of some of the exchanges.

It should not be necessary to argue that such questions merit serious consideration. Logically, no academic subject which purports to make a contribution to human knowledge can be unconcerned about its own epistemological foundations. This is particularly obvious when the discipline in question espouses a philosophical methodology.

So the questions left unanswered by the exchange between Kottow and Seedhouse need addressing, and it is incumbent upon those who contribute to bioethical debate to address them. To attempt to remain neutral about the nature of your own enterprise is in a very real sense to admit that you do not know what you are doing. If that is your predicament then you can hardly expect anyone else to take what you say very seriously.

I do not, here, consider the arguments of other bioethicists who have attempted to respond to Seedhouse. This is not because I think them unworthy of consideration. My reasons for the present focus on Kottow are as follows.

Firstly, Kottow raises issues about the appropriate style of the debate-what he calls matters of "form" as opposed to "content" — which needs to be considered and (hopefully) dispensed with before the debate can make progress. While I argue questions of methodology are central to understanding a discipline's identity, I do not think "form" in the sense Kottow uses the word is helpful. Indeed, it causes us to misunderstand what an argument is, betraying fundamental confusions.

Secondly, one reading of Kottow's position suggests that bioethics is not, in fact, a branch of philosophy and can abandon philosophical method. Yet many well-known bioethicists consider the subject a branch of analytical philosophy. It may be that people are doing radically different things under the same label, employing different methodologies for different purposes. (I explore this possibility in more detail elsewhere. $)^{4}$ If so, we should at least be clear about this. Only once we have identified what precisely it is that people think they are doing can we start to discuss sensibly which forms of bioethics (if any) are valuable and which (if any) need to be revised or abandoned altogether.

\section{HOW THE AUTHORS CHARACTERISE THE DEBATE}

Kottow's first article ${ }^{1}$ was a reply to previously published work by Seedhouse. ${ }^{5}{ }^{6}$ Its title indicates that Kottow sees himself as defending the very existence of the subject called "medical ethics" (or "bioethics" - both authors appear to use the terms interchangeably, and since I am unaware of any well worked out and universally accepted distinction between them I will do the same). In opposition to Seedhouse, Kottow argued that medical ethics is a bona fide "discipline", whose "major insight" is that "technical excellence" can be distinguished by proper analysis from "ethical considerations", and that the former "may well become subordinate" to the latter. ${ }^{7}$ It follows that a discipline can exist which studies the relationships between these distinct aspects of medical practice. It is apparently important to Kottow to establish that these aspects are part of the "essence" of medical practice, such that medicine is an "intrinsically ethical" activity. ${ }^{8}$ The relationship between this and his other claims is not spelled out, but as we will see it is of first importance. For now it is worth noting that, since Kottow believes himself to be defending the very existence of the subject, the way in which he goes about defending it should reveal some of his most fundamental beliefs about the nature and presuppositions of the purported "discipline" being defended.

At the "bioethical level of analysis" medical ethicists will "distinguish and comment on the 
values involved in medical practice" ${ }^{8}$ In response to Seedhouse's criticism that bioethicists artificially isolate medical practice and the moral concerns it generates from the broader social context, ${ }^{9}$ Kottow states that "it is by no means made clear why a bioethicist should be the appropriate consultant concerning unequal familial wealth distribution outside of a health care scenario". ${ }^{10} \mathrm{He}$ concludes by suggesting that medical ethics can make a "contribution" to "solving clinical and public health dilemmas" thus increasing the "ethical excellence" of clinical decisions. ${ }^{11}$

In his reply, ${ }^{3}$ Seedhouse criticised Kottow's article on four counts. According to Seedhouse, too much work in bioethics:

1. fails to seat ethical analysis in a social context;

2. is implicitly conservative;

3. is guilty of poor scholarship, and

4. is similarly guilty of inadequate reasoning.

and he cites Kottow's work as an illustration of all of these failings. ${ }^{12}$ Seedhouse supports each of these claims with fairly detailed and specific reference to Kottow's article, and I will return to some of his substantive points shortly.

It is Kottow's response to these criticisms, in his second contribution to the debate, ${ }^{2}$ that I found particularly perplexing. In the opening paragraph he complains of Seedhouse's use of "fierce language" and "ad hominem rhetoric", before stating that since he is not "well disposed" to such rhetoric, he "will concede Mr Seedhouse all the points he wishes to make and let them stand against my paper". The rest of the article is a series of numbered points which (despite the claim to have conceded "all the points" made by Seedhouse) appear to be attempted responses to several of the points Seedhouse makes. Indeed, the abstract states that the claims which Seedhouse makes about "slovenly scholarship" are "easily refuted", strongly suggesting that far from conceding all the points Kottow thinks he is refuting at least some of them.

Reading the numbered points, I felt an unexpected attraction to certain radical positions in epistemology, that make the (paradoxical if not patently self defeating) claim that no one can ever really understand what anyone else says. Not only do the nine points fail to address systematically the four main criticisms in the Seedhouse paper, there is no clear sense in which they represent anything I can recognise as a "defence", either of the first article in the debate, or of bioethics in general. The points read less like a structured refutation and more like a series of retorts which (despite the numerical ordering) have no intended logical order. What does come across very clearly, however, is a feeling: the strong sense that Seedhouse's comments are impertinent-both in the sense that they are intellectually beside the point and that they are in some way contrary to proper academic behaviour, violating what Kottow (citing Habermas) calls the "ethics of ethical discourse" ${ }^{\prime 13}$ Similarly Seedhouse feels that Kottow is being evasive (hence the reference to "camouflage" in the title of his article) and assuming the role of apologist for the status quo, "with all its inequity and greed". ${ }^{14}$

So we have two evidently literate and knowledgeable authors taking up stances that are in some obvious way opposed to each other, but the precise nature of their disagreement is not transparent, and each party thinks the other confused and/or reprehensible for taking up the stance he does. When an argument appears to be at cross-purposes, when differences seem intractable and further exchanges futile, one very common philosophical strategy is to examine the contributors' underlying assumptions, so that we may at least have a clearer sense of what the issue is that divides them. Discovering these assumptions evidently requires analysing what they actually say, so it will be necessary to look in a little more detail at the criticisms Seedhouse levels at Kottow, and Kottow's responses, before considering whether it is possible to form any conclusions about the presuppositions of bioethical discourse on the basis of this philosophical exercise.

\section{SEEDHOUSE ON THE FOUR FAILINGS OF BIOETHICS}

The first of the four criticisms noted above is the most important. Seedhouse has argued at some length ${ }^{5} 9^{15}$ that many bioethicists are at fault for discussing the problems of the health service in isolation from broader political questions about the social context in which health services are provided. It strikes me that there are really two, related points at work here.

The first concerns the sense in which ethical discourse is "prescriptive". While there is no reason to infer that Seedhouse is committed to any specific form of the metaethical doctrine called "prescriptivism", ${ }^{16}$ it is clear that he thinks ethical discourse is prescriptive in at least the following sense: that its intended object is a practical conclusion, meaning one with logical implications for action (hence his claim that "the ethical realm is where each of us can affect others' lives for better or worse" ${ }^{12}{ }^{12}$ It follows that any purported "ethical" discussion which is in fact incapable of affecting practices is not the genuine article. Bioethics, then, is not a proper branch of ethics if it produces statements about what ought to be done which have no clear applications, given the real nature of the social world.

The second point is that problems and practices in health care are "inextricably connected to other parts of the social world" ${ }^{\prime 17}$ : any meaningful discussion about how to affect them must take account of the need to affect changes in the wider social order, and the limitations placed upon the discourse by the non-rational nature of the context it aims to affect. It is therefore intellectually arbitrary to analyse the moral problems within what Kottow calls the "health care scenario"10 without tackling broader political questions-about the nature of social justice, the irrationality and brutality of the social order, and the real empirical and conceptual problems surrounding the question of how one meaningfully goes about affecting social change.

Thus Seedhouse is not making the crude claim that the "adequacy of ethical analysis" is "to be measured by its actual impact on decisions and policies" ${ }^{10}{ }^{10}$ Rather he is stating that the problems which bioethicists discuss cannot be adequately addressed while remaining within the arbitrary limits (upon the proper subject matter of bioethical debate) that some bioethicists seem determined to observe. The targets of his criticism, then, are those bioethicists who think, like Kottow, that it is not clear why "a bioethicist should be the appropriate consultant" concerning "distribution outside of a health care scenario". ${ }^{10}$ It is not, for Seedhouse, a matter of which "consultant" to speak to about which ethical problems: it is the very idea of ethical discourse which underlies this comment that he rejects.

The second of the four criticisms is a logical implication of the first. The attempt to find solutions to ethical problems (such as how to ration health services in a way that is "just" or "fair")" in isolation from any discussion of the broader social order which generates those problems betrays "implicit conservatism". One cannot simply posit the context as a given, uncritically, and expect to find a tenable solution. For to assume that one can find "just" solutions to the distribution of health resources given a particular social context is (logically) to assume that there is nothing in the nature of that context that precludes a just solution: in short, that the context is not inherently unjust. This is not to remain neutral with regard to the morality of that context; it is implicitly to endorse it.

So if medical ethicists were prepared to defend openly their assumptions about what sort of social arrangements are morally acceptable-which inequalities of power, wealth, and opportunity they deem justified, for instance-then Seedhouse (if my reading of him is correct) would welcome the ensuing broadening of the debate, even if he disagreed with the specific assumptions being defended. On the other hand, 
if they insist upon taking the status quo at the time of their writing as their intellectual starting point (stating, with Kottow, that "a bioethicist" is not the "appropriate consultant" for such deep and challenging questions) then they effectively endorse, without argument, whatever arrangements are in place. In that case they allow non-rational, unanalysed social relations to define their academic remit, and they can only succeed in providing a gloss of moral language for systems and policies which would be in place in any case, regardless of their debate.

What of the other criticisms? The evidence of "poor scholarship" in Kottow's paper seems pretty overwhelming, although the extent to which this reflects upon standards in bioethics in general is another question. Seedhouse shows that Kottow makes patently false claims about the history of ideas $^{718}$ and either has not read, or has read inattentively, articles he cites as his primary sources. ${ }^{8}{ }^{19}$ Furthermore, he speculates (incorrectly) upon the content of a text which he clearly has not read, founding criticisms of the author upon this speculative exercise. ${ }^{820}$

As for "inadequate reasoning", Seedhouse complains that Kottow persistently fails to define his key terms, allowing for fallacies of ambiguity in his argument ${ }^{12}$ and enabling him to treat contentious claims and contested concepts as if their meaning were obvious. ${ }^{11}{ }^{14}$ Kottow also fails to provide appropriate evidence or argument for the inferences he makes. For instance, he states that the sort of "bioethical analysis" he favours can "enrich the texture" of "hunches and feelings" in a way that will make them "more generally acceptable"10 20 and that this style of analysis can reduce "conflicts between values and logic" in a way that leads to "equal respect for all involved"11 ${ }^{14}$ : yet, Seedhouse notes, he provides no example to explain what precisely is being envisaged, so his claims about the causal properties of bioethical analysis are "assertions passing for arguments".${ }^{14} \mathrm{He}$ moves directly from an empirical claim about the reliability of testing kits for Hepatitis $C$ to a conclusion about the morality of screening, without explaining (let alone defending) the moral premises that might make this inference valid, ${ }^{10}{ }^{20}$ and from an assertion Seedhouse makes about the need for carers to make "effective, sensitive decisions", Kottow inexplicably infers that Seedhouse can be "easily read" as advocating "a strong brand of paternalism". ${ }^{20}$

My interest here is not in these errors, surprising as they are, (we all make mistakes) but in Kottow's indignant response to the paper which points them out, and the assumptions it reveals about what is the appropriate methodology and content of work in the field of medical ethics. My own attempts to draw out Kottow's assumptions will necessarily be somewhat speculative, since (perhaps due to my ignorance) I know of no work of his which spells out his position in moral epistemology and its relationship with his conception of bioethical analysis. If this paper stimulates any further discussion of these foundational questions, from Kottow or anyone else, then it will have been successful.

\section{KOTTOW ON THE 'ETHICS OF ETHICAL DISCOURSE'}

As already noted, Kottow thinks that the style of Seedhouse's critique violates "the ethics of ethical discourse". In the abstract and opening paragraph of his counter-response, Kottow objects to Seedhouse's "unbridled" use of "ad hominem rhetoric". ${ }^{2}$ He supports this objection by pointing to the "fierce language" Seedhouse employs to accuse him of "precarious scholarship", making "ridiculous guesses" and being "blinded by convention"-language which Seedhouse "presumably" uses to "disqualify" Kottow and "put an end to the discussion".

What does Kottow mean by the terms "ad hominem" and "rhetoric", and how do they function as part of a legitimate objection to Seedhouse? Kottow is surely aware that there is scope for debate about the proper use of rhetoric in rational argument. Clearly some rhetorical devises are dubious: language may be employed to distort rather than discover the truth, or to conflate distinct points, or create the impression of an argument where in fact there is nothing of substance (privileging "form" over "content", ${ }^{12}$ a flaw Kottow attributes to Seedhouse). It is equally clear that not all uses of rhetoric are illicit: any argument involves the employment of rhetoric because an "argument" is (amongst other things) an attempt to convince. (Kottow accepts this since he criticises Seedhouse's arguments for failing to be "convincing". .)

To condemn an argument for being "rhetorical" is to imply it relies purely upon labelling, name-calling or some other form of verbal manipulation, failing to provide intellectually sound reasons to accept its conclusions. To accuse an author of the "ad hominem" fallacy is to suggest that he or she fails to address another author's arguments, resorting instead to a personal attack. Since, as we have seen, Seedhouse supports his criticisms with detailed and specific reference to Kottow's actual arguments, it is hard to sustain the charge that he commits this particular fallacy. Seedhouse does not simply evoke the labels "precarious scholarship" and the rest: he cites evidence of the various failings he attributes to Kottow's work. (What is more, Kottow says he is prepared to "concede all the points" Seedhouse makes in an argument designed to justify the employment of these terms.) Indeed, since Kottow employs the label "ad hominem", without justifying his use of that label, it is his own argument that seems "purely rhetori$\mathrm{cal}^{\prime \prime}$ in the reprehensible sense.

Why, then, does Kottow feel so offended? His numbered points provide clues. Kottow had implied ${ }^{7}$ that discussions of "how people die" and the views of Jehovah's Witnesses regarding blood transfusion were a relatively recent (mid-late twentieth century) phenomenon, a claim Seedhouse says it took him "twenty minutes" to refute. ${ }^{18}$ My first reaction was: why so long? Surely any educated person knows that debates about euthanasia, suicide and what it means to have a "good death" go back to the ancients, and the views of Jehovah's Witnesses date back to the radical Protestantism of such figures as Luther and Calvin. So I found Kottow's reply initially baffling. His fifth point ${ }^{2}$ cites a "disreputable" 1931 text on euthanasia, then cites work done in the 1970s on the same subject, commenting: "I quite distinctly perceive a sense of novelty in these and many other texts". Point six states that the Jehovah's Witnesses "did not emerge" until the 19th century. How do these points represent a "response" to Seedhouse, let alone support the claim that his accusations of "slovenly scholarship" are "easily refuted"?

The answer, I think, is to be found in a closer reading of Kottow's initial claim. What he actually said was that "how people die" became an "ethico-medical issue" in the 1950s, and the stand of Jehovah's Witnesses acquired "relevance" even later.' What does he mean by "relevance" and "ethico-medical" (given that both ethics and medicine existed prior to the 1950s)? Point six explains that "the first Supreme Court order" regulating medical intervention regarding "this sect's tenets" was in 1965, on the basis of which he concludes "my argument holds ... ethico-medical awareness of issues related to voluntary death is a contemporary concern". The sect existed for at least 100 years before becoming "relevant" to the sort of people Kottow sees his work as being for: those interested in debating the rules and regulations governing contemporary medical practice. The limits of his envisaged audience's "awareness" define the limits of "relevant" bioethical commentary.

This explains his response to the accusation that his dismissal of the criticisms made by Seedhouse in "numerous journal papers and nine books" 20 is based on "ridiculous guesses" about the content of those papers and books. Point seven of his reply states that he is "happy to join ranks" with others who misunderstand a distinction Seedhouse makes, 
even though he employed this distinction as part of his initial critique of Seedhouse. ${ }^{8}$ Point eight concedes that he had not read the work by Seedhouse which formed the basis of his accusation of "strong paternalism", explaining that he was not "interested" in reading the complete work but rather he was only interested in commenting upon the small portion of it Seedhouse had quoted in the Journal of Medical Ethics. Clearly Kottow thinks it inappropriate for Seedhouse to expect him to have read the whole text before criticising it (point nine notes that its arguments are "hardly listened to") which indicates he has a clearer idea of his academic remit than (for instance) I have of my own.

As a philosopher I am constantly humbled by my lack of knowledge of other academic disciplines. Having no clear sense of the limits of my subject, I see it as my duty to try to understand and respond to arguments from any area. Some postmodernist critiques of modern epistemology presuppose insights derived from the work of sociologists, and work in neurology provides the basis for an assault on many of my own beliefs about the nature of mental states. It would not occur to me to publish criticisms of such work without attempting to understand the thinking behind them, then to explain, when my criticisms missed the mark, that I was "not interested" in sociology or neurology. I am aware, however, that colleagues in other disciplines have been known to respond to philosophical criticisms by pointing out that they are not philosophers- the apparent implication being that they are under no obligation to consider objections from "outside" their academic remit.

Seedhouse, also, is a philosopher, which explains his outrage at what he certainly perceives as the dogmatism of Kottow's statements. (This is perhaps why I find Seedhouse's arguments so much easier to comprehend than Kottow's-we were trained in similar methods.) As a bioethicist, Kottow sees his academic role as "knowing enough about both medicine and philosophical ethics" to develop a "certain expertise" called "medical ethics". ${ }^{8} \mathrm{He}$ "distinctly perceives" something "new" and "novel" in this role. ${ }^{2}$ It therefore strikes him as frivolous or impertinent to expect him to consider points not derived from that specific area of expertise, such as ideas derived from social philosophy or pre-1950s debates on euthanasia.

So it may be that I was wrong to imply (see my opening comments) that bioethics espouses a "philosophical methodology". Clearly there is a difference between being a philosopher and "knowing enough" philosophy to be a bioethicist in Kottow's mould. To be a philosopher (at least, as I understand the term, and I suspect as Seedhouse understands it also) is to espouse a methodology that requires one to follow a line of reasoning to its logical conclusion, wherever it goes. In this sense philosophy is necessarily an impertinent discipline: it recognises no borders to its proper territory, so it is no respecter of limits, be they set by social conventions, the powers that be, or the declared interests of authors who come under its scrutiny.

Supposing I am correct, and Kottow's conception of bioethical methodology differs from that of philosophical methodology sketched here: what more can be said about the nature and assumptions of this "distinctly" bioethical methodology? (I must reiterate that I am speculating in an attempt to make sense of Kottow's statements. Also, my view of philosophical methodology might differ from his. Either way, if he points out where I have gone wrong, then hopefully we may begin to understand each other. The alternative is to treat mutual understanding as an impossible goal, and I am not yet prepared to accept that option.)

Kottow's first three numbered points ${ }^{2}$ seem to me key to understanding the assumptions about ethics which give sense to his views on medical ethics. Disputing Seedhouse's claim that all human actions have ethical content, point one states that actions "become ethical issues" when they "distort otherwise straightforward" interactions regulated by "social norms". In response to the very serious allegation that he fails to clarify the meaning of key terms, allowing for fallacies of ambiguity in his argument, ${ }^{12}$ point two states that ethics is a "language game" and "does not need to nor could have all its terms defined". Point three asserts that "the whole point" of his first paper was that "medical ethics is of the utmost importance" because there is a "gap between what medicine essentially is and the way it is practised" (my italics). As noted already, medicine is conceived by Kottow as possessing an "essence" which is "ethically benevolent", ${ }^{8}$ and moral

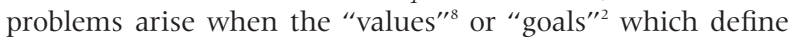
this essence are "ignored" ${ }^{2}$ by practitioners. These values "vary and shift according to social contexts", requiring ethicists "permanently" to be "vigilant". ${ }^{8}$

As a philosopher I have problems understanding how the "essence" of a thing can "shift" since if something's essence changes that is another way of saying that it is no longer the same thing, that it has ceased to be. The reference to "language games", however, is an allusion to Wittgenstein, ${ }^{21}$ perhaps suggesting the view that Seedhouse is wrong to demand a defence of Kottow's use of terms such as "fairness" and "rationality", since one can only look at how these terms are used in specific contexts: what people understand by "a fair race", to use Kottow's example, is to be understood by looking at which races are generally deemed "fair". This, along with his talk of "social norms" suggests that the ethical "expertise" Kottow prizes comes from a careful study of the conventions governing practices in the area being studied.

Kottow's position in moral epistemology would seem then to be this. Social practices (medicine included) have "essences" which include "ethical dimensions". ${ }^{8}$ To understand the ethics of any practice is to "distinguish and comment on" the values and goals which form its "essential" ethical aspects. Since these values can "shift" in accordance with changing conventions, proper bioethical analysis takes a knowledge of the relevant conventions as its starting point. (This would explain why debates about euthanasia in ancient times lack "relevance": the conventions have "shifted".) In contrast, Seedhouse's position in moral epistemology presupposes that it is meaningful (indeed imperative) to criticise the social conventions underlying practices: hence his rejection of Kottow's "implicit conservatism".

Of course questions can be raised about each position. Seedhouse's view seems (to me) to require some form of moral realism to make it tenable. That is to say, the criteria for the truth or falsity of moral judgments cannot be determined either by social convention or subjective whim, since it is possible for rational human beings to stand back from the social conventions which govern their current practices and to find that there are good reasons to approve of some conventions and to condemn others. In fact this is a view which I support, and which I explain and defend in detail elsewhere. ${ }^{22}$

With regard to Kottow's position, I am unclear how an ethicist knows which values represent the "essence" of a practice: certainly it is not clear how knowing any amount of moral philosophy can make this possible-so I cannot work out what Kottow means by "knowing enough" philosophical ethics. If it is simply a matter of understanding the "social norms" which "regulate" the practice (suggesting a discipline which owes more to sociology than philosophy) are we to take it that the "norm" in a given area cannot (as a matter of logic) be "unethical"? This would, indeed, be a recipe for extreme conservatism. Add the idea that the "norms" can "shift" and the position becomes profoundly ambiguous: how, then, do we know whether practices are increasingly departing from their ethical "essence" (a cause for moral concern) as opposed to that essence simply being in a state of "shift"?

Hopefully Kottow will not regard these questions as too simplistic to deserve a more considered response than his brief and indignant rebuttal of Seedhouse. (He should realise I am a philosopher and bound to ask such questions-if he likes, 
this is part of the "essence" of my practice and so is necessarily a good thing.) There are real questions about appropriate academic methodology which space dictates I can only raise here. Even if bioethical methodology differs fundamentally from philosophical methodology (which would suggest that bioethics is not, in fact, a branch of philosophical ethics, contrary to the impression generated by much writing in the area) it does not follow that bioethicists can simply dismiss philosophical criticisms by declaring them not "relevant": for you do not need to be a philosopher to be guilty of a philosophical error. On Kottow's account (again, if my attempt to reconstruct his position succeeds) bioethics is the attempt to answer evaluative questions-questions about how we should conduct ourselves-with reference to the values which do in fact govern practices in a given area at a given time. Yet if that is so the very project appears to beg all of the interesting questions about how we move from an "is" to an "ought" in moral thinking.

Even if my reading of Kottow is right, there may be many bioethicists who reject his account of what the subject is all about. If so then they need to explain why they think the criticisms raised by Seedhouse and discussed in this paper do not apply to them. Do they reject his call to broaden the debate to include fundamental questions of social and political philosophy? If so, what are their arguments, and what position in moral epistemology does underpin their position? My goal is not to "put an end to the discussion" but to ensure that it continues.

\section{REFERENCES}

1 Kottow MH. In defence of medical ethics. Journal of Medical Ethics 1999:25:340-3.

2 Kottow MH. A reply to Professor Seedhouse. Journal of Medical Ethics 1999;25:49-50.

3 Seedhouse DF. Camouflage is no defence-a response to Kottow. Journal of Medical Ethics 1999;25:344-8.

4 Loughlin M. Ethics, management and mythology. Oxford: Radcliffe Medical Press, 2001: see especially ch 6, note 19

5 Seedhouse DF. Against medical ethics: a philosopher's view. Medical Education 1991;25:280-2.

6 Seedhouse DF. Against medical ethics: a response to Cassell. Journal of Medical Ethics 1998;24:13-17.

7 See reference 1: 340-1.

8 See reference 1: 341 .

9 Seedhouse DF. Why bioethicists have nothing useful to say about health care rationing. Journal of Medical Ethics 1995;21:288-91.

10 See reference 1: 342 .

11 See reference 1: 343 .

12 See reference 3: 344 .

13 See reference 2: 350 .

14 See reference 3: 348 .

15 Seedhouse DF. Philosophy must fall to Earth. Health Care Analysis 1996;4:91-4.

16 Hare RM. The language of morals. Oxford: Oxford University Press, 1983.

17 See reference 15: 94 .

18 See reference 3: 345-6.

19 See reference 3: 346 .

20 See reference 3: 347 .

21 Wittgenstein L. Philosophical investigations Oxford: Basil Blackwell, 1989.

22 See reference 4: in particular section 4. 